Edvânia Ângela de Souza Lourenço ${ }^{1}$ Francisco Antonio de Castro Lacaz ${ }^{2}$

\section{Os desafios para a implantação da política de Saúde do Trabalhador no SUS: o caso da região de Franca-SP}

\author{
Challenges for implementation of Brazilian National \\ Occupational Health Policy in the Unified Health System \\ (SUS): the case of the region of Franca, São Paulo, Brazil
}

${ }^{1}$ Departamento de Serviço Social, Faculdade de Ciências Humanas e Sociais, Universidade Estadual Paulista (Unesp). Franca, SP, Brasil.

${ }^{2}$ Departamento de Medicina Preventiva, Escola Paulista de Medicina, Universidade Federal de São Paulo (Unifesp), São Paulo, SP, Brasil.

Contato:

Edvania Ângela de Souza Lourenço

E-mail:

edvaniaangela@hotmail.com

Este texto discute os dados parciais do projeto de pesquisa "O processo de trabalho na agroindústria canavieira: os desafios para o Sistema Único de Saúde (SUS) e Sindicatos dos Trabalhadores", financiado pelo CNPq, conforme edital 02/2010, sob número 401.159/2010/8, e aprovado pelo Comitê de Ética em Pesquisa da Faculdade de Ciências Humanas e Socais (FCHS) da Universidade Estadual de São Paulo (Unesp), Franca. Processo $n^{\circ}$ 023/2010.

Os autores declaram que este trabalho não apresenta conflito de interesses.

\section{Resumo}

O artigo oferece subsídios teórico-práticos para a análise da Atenção à Saúde do Trabalhador desenvolvida pelo Sistema Único de Saúde (SUS). A partir de um lócus determinado, a região de Franca, interior do Estado de São Paulo, busca-se identificar os desafios da implantação da política de saúde do trabalhador frente às especificidades da relação trabalho e saúde na agroindústria canavieira. Toma como referência entrevistas coletivas realizadas com trabalhadores da saúde, especificamente os fiscais sanitários e os interlocutores em saúde do trabalhador. Como resultado, verifica-se a necessidade de maior preparação técnica para os profissionais desenvolverem as ações de saúde do trabalhador e maior integração entre os serviços, sobretudo no que diz respeito às notificações dos agravos e às ações de vigilância em Saúde do Trabalhador.

Palavras-chave: saúde pública; saúde do trabalhador; vigilância em saúde; notificação compulsória; trabalho rural.

\begin{abstract}
This article offers theoretical and practical elements for an analysis of the Worker's Health Care Program developed by the Brazilian Unified Health System (SUS). From a determined locus, the region of Franca, State of São Paulo, it aims at identifying the challenges for implementation of the National Occupational Health Policy, due to the particularities of the work/health relationship within the sugarcane agro-industry. It is based on group interviews involving health workers, specifically sanitary inspectors and the worker's health interlocutors. The results showed that health care professionals must be better prepared, from the technical point of view, to be able to perform actions related to workers' health. These results also indicated the need for a greater integration between health services, particularly when damage notification and workers' health surveillance are concerned.
\end{abstract}

Keywords: public health; worker's health; health surveillance; mandatory notification; rural labor. 


\section{Introdução}

A respeito do campo Saúde do Trabalhador (ST), pode-se dizer que, no Brasil, a partir do contexto econômico, social e político dos anos de 1980, vem-se estruturando uma rede de serviços como parte do Sistema Único de Saúde (SUS) para: assistir todo trabalhador vítima de agravo à saúde; identificar a relação do agravo com o trabalho; realizar os registros epidemiológicos e, ainda, ações de vigilância nos ambientes de trabalho (DIAS, HOEFEL, 2005; LACAZ, 2010; MINAYO-GOMEZ, 2011).

Atualmente, a ST no SUS busca disseminar suas ações para os vários serviços, não mais se concentrando em um único órgão, no caso, o Centro de Referência em Saúde do Trabalhador (Cerest). Tais centros, a partir do que é preconizado pela Rede Nacional de Atenção Integral à Saúde do Trabalhador (Renast), a par dos princípios e das diretrizes do SUS (BRASIL, 2002, 2005, 2009b), têm a responsabilidade de inserir a ST na Atenção Básica, considerando as Unidades Básicas de Saúde (UBS) e a Estratégia Saúde da Família (ESF), e também na média e na alta complexidade. Com isso, visa desenvolver ações que vão além da assistência e que garantam a prevenção, a promoção, a vigilância e um sistema de informação capaz de oferecer dados acerca das condições de trabalho e saúde a fim de nortear ações mais efetivas na prevenção dos males à saúde (MAENO; CARMO, 2005; DIAS; HOEFEL, 2005; LACAZ, 2010; MINAYO-GOMEZ, 2011; SANTOS; LACAZ, 2011).

A estruturação das ações de saúde do trabalhador no SUS está ancorada diretamente nas mudanças conceituais que se deram a partir da formulação do campo de práticas e saberes denominado Saúde do Trabalhador (ST). Diferentemente da Medicina do Trabalho e da Saúde Ocupacional, a ST considera o trabalhador como sujeito de saber e, portanto, ele deve participar do desenvolvimento das ações, sobretudo por meio dos Conselhos Gestores e das Comissões Intersetoriais de Saúde do Trabalhador CIST (LACAZ, 1996, 2007).

Do início do século XXI até os dias atuais, o campo da ST vem buscando ampliar espaço no interior do SUS. Tal estratégia tem provocado o aumento contínuo das ações, habilitando Cerests em todos os Estados brasileiros, sendo que só no Estado de São Paulo concentram-se 45 centros de referência de abrangência regional dentro da já citada estratégia da Renast (LACAZ, 2010).

Lacaz (2010) explicita que a ST no SUS vem sendo desenvolvida por meio dos Cerests regionais e implementada por meio de, pelo menos, duas vertentes: rede sentinela e vigilância em saúde. A rede sentinela condiz com a preparação e a capacidade técnico-ope- rativa dos serviços de saúde em diagnosticar, prevenir, tratar e notificar os agravos à saúde dos trabalhadores. Sublinha a importância da preparação técnica dos trabalhadores da saúde para reconhecer a centralidade do trabalho no processo saúde-doença e, ainda, aponta para a necessidade de alimentar o sistema de informação, o que, em tese, possibilita a criação de um observatório regional cujos holofotes podem iluminar o planejamento de ações sistemáticas para a interrupção destes problemas.

A Vigilância em ST (Visat) deve estar integrada ao conceito de vigilância em saúde, considerando a necessidade de articulação das vigilâncias sanitária, epidemiológica, ambiental e dela própria (LACAZ, 2010).

Um grande desafio para a implantação de uma Política Nacional de Saúde do Trabalhador é a integração entre os vários Ministérios - Saúde, Previdência Social e Trabalho e Emprego -, pois, como aponta Lacaz (2010), ainda persiste uma verdadeira salada institucional, com atribuições e normatizações específicas de cada um e uma fragmentação de atribuições, apesar da implementação da Política Nacional de Segurança e Saúde do Trabalhador sancionada pela Presidência da República (BRASIL, 2011b).

Minayo-Gomez (2011), ao discutir o campo ST, chama a atenção para alguns avanços, mas também para limites do campo. Pelo lado da produção do conhecimento científico, destaca a pluralidade de pesquisas que vêm sendo feitas com enfoque na relação trabalho e saúde, envolvendo várias áreas do conhecimento e instituições de ensino-pesquisa. Todavia, segundo sua análise, muitos desses estudos ainda carecem de maior aprofundamento conceitual e metodológico, além de permanecerem distantes da rede de serviços e políticas sociais (MINAYO-GOMEZ, 2011).

No âmbito do SUS, apesar do estabelecimento das diretrizes da Política Nacional, de suas atribuições e definições regulatórias, ainda não foi possível construir um panorama da situação da saúde dos trabalhadores no Brasil, considerando as dificuldades de um amplo diagnóstico. Outros problemas, segundo Minayo-Gomez (2011), como a ausência de ações integradas e intersetoriais, de avaliações das ações, o distanciamento das universidades e dos programas de pós-graduação da rede de saúde, a histórica dicotomia entre os ministérios da Saúde, Previdência e Trabalho, entre outros, impõem sérios limites às ações de ST no SUS. O autor chama atenção também para a necessária articulação e integração da questão ambiental com a ST.

Vasconcelos e Machado (2011) enfatizam o não reconhecimento do papel do SUS no que tange às ações em ST no Plano de Aceleração do Crescimento (PAC) e, dentre outros, nos projetos "desenvolvimentistas" financiados pelo Banco Nacional de Desenvolvimento Social (BNDES). 
Considerando o contexto acima traçado, este texto objetiva trazer subsídios para o debate que gira em torno da implantação das ações de saúde do trabalhador no âmbito do SUS, com enfoque para o setor agroindustrial canavieiro, a partir da experiência regional de Franca, SP. A tarefa é pensar como os profissionais que estão na ponta dos serviços de saúde veem a ST e quais as principais ações e desafios a desenvolver e enfrentar, sobretudo frente ao avanço do setor agroindustrial canavieiro.

\section{Método}

A região contemplada pelo Cerest, regional Franca, a partir do princípio de regionalização e hierarquização, é constituída por vinte e dois municípios, em termos da administração da saúde, subdivididos em três microrregiões: Alta Anhanguera (composta de seis municípios: Ipuã, Morro Agudo, Orlândia, Nuporanga, Sales Oliveira e São Joaquim da Barra); Anhanguera (com sete municípios: Aramina, Buritizal, Guará, Ituverava, Igarapava, Jeriquara, Miguelópolis); e Três Colinas (composta de nove: Cristais Paulista, Franca, Itirapuã, Patrocínio Paulista, Pedregulho, Restinga, Ribeirão Corrente, Rifaina e São José da Bela Vista). Os vinte e dois municípios somam cerca de 700 mil habitantes (INSTITUTO BRASILEIRO DE GEOGRAFIA E ESTATÍSTICA, 2010).

Para discutir os desafios do SUS frente à saúde dos trabalhadores do setor agroindustrial canavieiro, foram realizadas entrevistas coletivas, na forma de oficinas, com os trabalhadores dos vários serviços de saúde da região e entrevistas individuais com representantes das usinas, dos sindicatos e trabalhadores deste setor. Também foram realizadas visitas aos serviços de saúde dos municípios da região e levantadas as notificações dos agravos à saúde dos trabalhadores, especificamente do setor agroindustrial canavieiro, considerando o período de 2005 a 2010.

Para a especificidade deste texto, foram selecionados apenas os depoimentos referentes às oficinas com profissionais da saúde da região de Franca, compreendendo os Interlocutores em Saúde do Trabalhador (IST), os quais são responsáveis pela implantação das ações de saúde do trabalhador no seu município, e os fiscais sanitários.
A coleta de dados por meio de oficinas, conforme discutido por Ribeiro (2005), cria um ambiente propício para a discussão da situação-problema pelos participantes, porque prevê mais de um encontro, ou seja, há uma continuidade da discussão, e também pelo fato de os sujeitos terem em comum o mesmo objeto de trabalho, neste caso, são trabalhadores da saúde responsáveis pela ST no seu município, o que contribui para o debate e a busca de enfrentamento dos problemas identificados.

Ao todo foram realizadas quatro oficinas no segundo semestre de $2011^{3}$. Todas foram gravadas, filmadas e o conteúdo dos depoimentos foi transcrito. A representação de cada município, nas oficinas, contou com mais de uma pessoa, com média de trinta participantes em cada encontro. Todos os participantes assinaram o Termo de Consentimento Livre e Esclarecido enviado com antecedência aos municípios.

Como um dos municípios não autorizou a divulgação do respectivo nome, apesar de ter autorizado a participação do seu funcionário, trabalhador da saúde, nas oficinas, definiu-se que a denominação das falas dos fiscais sanitários e dos ISTs utilizadas neste texto deveria ser identificada apenas por trabalhador da saúde seguido da região a que pertence, Alta Anhanguera, Três Colinas ou Anhanguera. Optou-se por fazer a denominação sempre no masculino por acreditar-se que a referência é o ser humano - ser social.

\section{Resultados e discussão}

\section{a) Agravos à saúde dos trabalhadores: reconhecendo o problema como problema}

Em estudo anterior, buscou-se documentar e discutir as ações de saúde do trabalhador desenvolvidas pelo Cerest, regional-Franca, implantado em 2004 (LOURENÇO, 2009). A partir desse estudo, pode-se afirmar que o Cerest vem desenvolvendo ações em ST com representantes da Direção Regional de Saúde (DRS) VIII, do Grupo de Vigilância em Saúde (GVS) e dos 22 municípios que compõem a região. Estas ações abrangem desde encontros e fóruns de discussão acerca da política de ST até ações concretas de investigação de acidentes e doenças relacionadas ao trabalho, implantação dos Relatórios de Atendimento aos Acidentes de Trabalho (RAAT) e da notificação

\footnotetext{
${ }^{3}$ As oficinas ocorreram nos dias um e dois de setembro, seis de outubro e oito de novembro de 2011. As duas primeiras oficinas ocorreram no salão de reuniões da Direção Regional de Saúde (DRS VIII) e as demais na Unesp-Franca. Ao final deste estudo, será realizada a quinta (última) oficina com os trabalhadores da saúde com o objetivo de socializar os dados. A realização das oficinas contou com a participação e o apoio das professoras Raquel Santos Sant'Ana e Onilda Alves do Carmo (Unesp-Franca), do Cerest regional Franca, da DRS VIII, do Grupo de Vigilância em Saúde (GVS) regional de Franca. Destaca-se também o apoio do Centro de Vigilância em Saúde da Secretaria de Estado da Saúde (CVS/SES-SP), especificamente a área de Saúde do Trabalhador que acolheu esta proposta e inclusive participou de uma das oficinas.
} 
compulsória dos agravos graves, fatais e que envolvam crianças e adolescentes, como proposto pelo Sistema Nacional de Informação de Agravos de Notificação - Sinan-NET (BRASIL, 2004; 2011a).

A respeito da notificação, como será discutido adiante, é importante enfatizar que, em geral, ela depende dos profissionais da saúde, inclusive dos médicos, a quem cabe reconhecer o problema como relacionado ao trabalho e notificá-lo. Assim, tanto o RAAT, que é um instrumento epidemiológico para o registro de qualquer agravo à saúde dos trabalhadores (independentemente do seu vínculo empregatício), quanto o Sinan-NET, que é uma exigência legal para a notificação de onze agravos (BRASIL, 2004; 2011a), dependem da informação dos trabalhadores em geral, da ação dos profissionais da saúde para suscitar tal preenchimento, bem como de seu compromisso ético e político com a ST. Há de enfatizar também o papel dos gestores da saúde para que estas ações sejam efetivadas.

O Cerest, apesar de atuar regionalmente, não tem poder para interferir na gestão dos municípios. Dessa forma, a implantação do RAAT, nesta região, não foi acompanhada de nenhuma lei, mas apenas do trabalho "socioeducativo" dos técnicos do Cerest regional com os interlocutores em ST e também com os gestores em reuniões programadas junto à DRS local.

O Cerest, visando disseminar a política de ST nos 22 municípios de sua abrangência, necessita contar com o envolvimento de representantes destes municípios - os ISTs -, indicados pelos gestores municipais. Portanto, antes do Cerest ter contato com os ISTs dos vários municípios, é necessário realizar um trabalho com o gestor municipal para que ele defina um funcionário (o Interlocutor) para articular as ações de ST no seu município, o que demanda vários contatos e participação nas reuniões do Colegiado de Gestão Regional ${ }^{4}$ para obter o compromisso do gestor com a defesa da ST. Ocorre que os gestores da saúde nem sempre se mantêm no cargo, uma vez que, durante um único mandato de governo municipal, podem passar dois ou mais gestores da saúde e essas mudanças não se fazem sem afetar a continuidade das ações, sendo comum mudarem também os responsáveis pelas várias políticas. Outras vezes, por não identificação do IST indicado com as ações em ST, acaba ocorrendo a mudança deste profissional. Assim, nos vários municípios, ocorre a descontinuidade das ações, como se observa na fala a seguir:

Oh, hoje, a gente quase não desenvolve. Lá no comecinho, quando saiu a história da Saúde do Trabalhador, que teve aqueles cursos, aí lá bem no começo, alguém aqui foi fazer algumas visitas... acompanhar o corte de cana; hoje, a nossa cidade, assim, basicamente não está fazendo... (Trabalhador da Saúde, Anhanguera)

A partir das oficinas, verifica-se que, se em um determinado momento a realização de cursos e reuniões favoreceu o início das ações em ST, a não continuidade dessas atividades (de capacitação e de acompanhamento da implantação da ST na região) - que é papel precípuo do Cerest - cria um vácuo entre o que é proposto e o que vem sendo feito:

[...] esse processo de RAAT, Saúde do Trabalhador, faz pouco tempo... Antes, assim, a gente não tem conhecimento se tinha uma pessoa responsável por isso, eu acho que não tinha... nem o RAAT... (Trabalhador da Saúde, Três Colinas)

Observa-se que a construção de um sistema de informação que ofereça uma fotografia dinâmica da relação trabalho e saúde está dependente da estrutura dos serviços de saúde no que tange à sua capacidade de diagnosticar, tratar, prevenir e notificar os agravos à saúde dos trabalhadores. Tal capacidade também está dependente da formação dos técnicos, portanto, as normatizações técnicas da ST no SUS devem ser articuladas ao processo de educação permanente dos trabalhadores da rede para rever a atenção tradicional baseada no modelo médico-assistencial e, sobretudo, reconhecer a determinação social do trabalho nos processos saúde-doença.

Ademais, o mecanismo de formação deve estar articulado à Política de Educação Permanente do trabalhador do SUS. Isto pode favorecer o reconhecimento do "problema como problema", como foi enfatizado durante as oficinas: "Antes a gente nem pensava nessa coisa de Saúde do Trabalhador" (Trabalhador da Saúde, Anhanguera) e favorecer a autonomia do profissional, que, ao reconhecer o "problema como problema", poderá buscar a interlocução com os diversos setores, a articulação com os demais profissionais e servidores do SUS, bem como a efetivação das ações de ST. No entanto, este técnico não pode ser visto como o "messias" que resolverá todos os problemas relacionados à efetivação das ações de ST. Na realidade, ele é apenas o interlocutor, ou seja, o responsável em fazer a comunicação com o gestor municipal e os demais responsáveis pelos serviços de saúde do seu município com a intenção de colocar em prática tais ações. Assim, o interlocutor não estará isento dos revezes da organização do trabalho na administração pública e das questões políticas e econômicas a ela relacionadas.

\footnotetext{
4 “Para qualificar o processo de regionalização e garantir o exercício da ação cooperativa entre os gestores, em cada Região de Saúde é constituído um Colegiado de Gestão Regional (CGR), com a participação de todos os municípios da região e da representação do estado. A constituição do CGR é uma etapa da regionalização que, para o pleno funcionamento, requer que os instrumentos de planejamento, a regulação, a programação e a ação coordenada entre os gestores sejam efetivos e permanentes" (BRASIL, 2009a).
} 
Durante as oficinas e também a partir das visitas aos serviços de saúde desta região, em contato específico com o IST ou fiscal sanitário, observou-se que a mudança de interlocutor, quando ocorre, não é de modo programado, sendo comum a interrupção das ações por tempo indeterminado até que outro representante assuma seu papel. Este, por sua vez, nem sempre garante continuidade do que vinha sendo desenvolvido, pois, em alguns municípios que tiveram troca do interlocutor, não se localizou os RAATs referentes ao período de ação do IST que havia saído. Eles simplesmente desapareceram ou reduziram abruptamente.

[...] a interlocutora da saúde anterior era enfermeira padrão chefe, né, do posto de saúde. Então ela tava diretamente ligada com as enfermeiras que preenchiam as RAATs, então assim, ela cobrava essa função. E hoje, como ela já não está mais participando do Cerest... não tá tendo cobrança pras enfermeiras que preenche e aí acabou ficando assim, mas a gente percebe que quando ela era interlocutora tinha muitas RAATs, muitas, e agora quando você foi lá, deu pra perceber isso, tem três ou quatro no ano... (Trabalhador da Saúde, Anhanguera)

Uma limitação importante é que, na realidade, a dimensão ampla de ST fica dependente de ações de um profissional que, por algum motivo, foi indicado pelo gestor da saúde do município para participar das reuniões e demais atividades promovidas pelo Cerest, pela DRS ou pelo GVS, como se pode observar no depoimento que se segue:

[...] nós tamo sempre reunindo com o pessoal, conversando, debatendo, então, essa parte assim, nós tamo bem esclarecidos com relação ao Cerest. Mas a gente sai daqui frustrado pela questão de não poder fazer nada do que a gente recebe aqui; então nós sabemos o que é preciso, o que tem que fazer, mas, aí chega lá no município, já fica mais complicado de tá desempenhando um papel (Trabalhador da Saúde, Anhanguera)

Observa-se que o técnico, aqui denominado Interlocutor em ST, deve receber as orientações passadas pelos órgãos citados e tentar implantá-las em seu município. Daí decorre uma primeira e grande dificuldade que é a falta de poder e autonomia desse técnico para incluir as ações na agenda do seu município ou no Plano Municipal de Saúde, como mencionado pelo interlocutor: “[...] aí chega lá no município, já fica mais complicado de tá desempenhando um papel" (Trabalhador da Saúde, Anhanguera).

Essa é uma questão que diz respeito ao reconhecimento da ST como um campo a ser abarcado pela política pública de saúde. Um segundo problema, e que muitas vezes se relaciona a esse, é que, quando o IST começa a ter uma preparação técnica e, portanto, sente-se mais seguro para discutir no âmbito local as ações de ST, acaba sendo substituído. Assim, o Cerest, a DRS e o GVS estão sempre recomeçando o processo de formação em ST, que deveria ser continuado, mas que recomeça do zero sempre que há substituição do técnico: "[...] eu venho aqui de paraqueda. Porque chega pra nós assim..., que, veja, faz pouco tempo que eu entrei nessa área de Saúde do Trabalhador" (Trabalhador da Saúde, Três Colinas).

Eu acho que uma das dificuldades que a gente tem
[...] é a falta de recurso humano que o município
enfrenta, todos os municípios menores enfrentam
isso [...] na verdade, Programa Saúde do Traba-
lhador, você não tem nem quem colocar. Então,
fulano, você vai lá, aí você vai, mas e aí? Ele não
tem disponibilidade pra tá desenvolvendo nenhum
programa, nenhuma ação[...] (Trabalhador da Saú-
de, Anhanguera)

Com isso, o cenário que se forma é o da heterogeneidade, da fragmentação e da descontinuidade das ações.

As ações de ST estão dependentes também da orientação da gestão. Se o gestor municipal não as vê como um foco importante da sua administração, acaba não designando um técnico para atuar no campo. Em consequência, se o município não designa uma pessoa ou constituí um setor específico para coordenar e efetivar tais ações, acaba favorecendo suas frequentes rupturas e a descontinuidade, como já indicado. Assim, é comum ouvir que antes se fazia determinadas atividades, mas houve interrupção, porque mudou o responsável pela ST no município ou mesmo as orientações dadas pelo Cerest.

Os depoimentos indicam a ausência de recursos humanos (e financeiros) e falta de vontade política em definir um técnico responsável para desenvolver as ações de ST. Neste sentido, destaca-se que a Renast prevê o repasse de verba para as ações de ST, o que vem sendo indicado como um facilitador para o reconhecimento deste campo de práticas e conhecimentos nas agendas municipais (SANTOS; LACAZ, 2011). Contudo, o fato da verba ser direcionada para os Cerests, que são regionais e geridos por determinado município, dificulta a ação no que se refere à alocação dos recursos regionalmente (LOURENÇO, 2009).

Lacaz (2010) indica que a regionalização dos Cerests significa a abrangência de uma população de mais de 500 mil habitantes. Na região em foco, o contingente populacional atinge cerca de 700 mil habitantes. Tal realidade acaba por impedir uma ação regionalmente eficaz, inclusive porque não se trata apenas do tamanho da população, mas também da diversidade dos problemas, que podem variar daqueles de uma realidade rural para outra eminentemente urbana. 
Acredita-se que, quando o gestor conhece e defende o SUS, há uma possibilidade maior de realizar as ações de prevenção e promoção da saúde, mas quando ele tem um perfil meramente político, as ações tendem a sofrer rupturas com mais frequência. O perfil do técnico que assume as ações em ST também deve ser considerado. Se este tem interesse, acaba participando mais das reuniões e também incentivando a implantação das diretrizes de ST no seu município. Por outro lado, se não tem interesse e, por algum motivo, foi designado apenas para representar o município, acaba absorvendo o conteúdo sem a preocupação de transmiti-lo aos demais trabalhadores da saúde do seu município e, como nem sempre há cobranças, continua participando dos cursos e demais atividades sem buscar meios de implementar as ações em sua cidade.

\section{b) A importância da notificação dos agravos em saúde dos trabalhadores e sua inconstância}

A inconstância das ações de ST no SUS reflete na notificação dos agravos à saúde dos trabalhadores e, num efeito dominó, a ausência desses dados favorece à descontinuidade das ações. Na região de Franca, constata-se, por meio das oficinas e também do levantamento estatístico das notificações dos agravos à saúde dos trabalhadores, considerando especificamente o setor agroindustrial canavieiro no período de 2005-2010, que os registros dos agravos apresentam uma oscilação muito grande. Assim, há ano que determinado município se destaca pela quantidade de agravos notificados, mas, no ano seguinte, apresenta uma queda considerável. A inconstância da notificação pode estar relacionada, entre outros fatores, ao papel desempenhado pelo responsável pela ST, ou seja, se esse profissional tem autonomia para implantar as ações e se realiza acompanhamento e cobrança nos serviços de saúde para que haja a notificação dos agravos, é possível que esses registros se mantenham. Todavia, na falta desse profissional, as notificações diminuem ou desaparecem:

[...] nós tamos com muitas dificuldades no preenchimento das RAAT, é, [...], faz quatro meses que não tem uma RAAT preenchida lá, e por mais que a gente converse, com o pessoal, com os responsáveis, ninguém faz nada [...] Então a gente fica um pouco de mãos atadas... (Trabalhador da Saúde, Anhanguera)

[...] é igual em qualquer cidade, o atendimento rápido, atender em vários lugares ao mesmo tempo, até porque tem poucos médicos no município.... eles não perdem muito tempo de fazer o nexo da doença com o trabalho. Então, hoje em dia, a gente vê muito isso mesmo, não notifica. (Trabalhador da Saúde, Alta Anhanguera)

[...] Chega um problema e a médica quer fazer o RAAT, mas pede algum exame, por exemplo, raio-x pro paciente, mas o paciente não volta, então ela não dá continuidade naquela RAAT, entendeu? (Trabalhador da Saúde, Três Colinas)
Além das mudanças na gestão da saúde destes municípios, que se relaciona à troca do profissional que desempenha o papel de IST e à autonomia que tem para desenvolver as ações de ST, verifica-se também a coexistência de outras questões que dificultam os registros dos agravos. Os depoimentos indicam a falta de autoridade do interlocutor ou a ausência de esforços nos municípios para exigir que os acidentes e as doenças relacionados ao trabalho sejam notificados, o que se associa também com a brevidade do atendimento médico e as dificuldades para a conclusão dos RAAT, quando se necessita de algum exame para caracterizar o diagnóstico, por exemplo. São questões diretamente ligadas com a organização e a gestão dos serviços de saúde.

Além da falta de um direcionamento normativo dos municípios quanto à necessidade de se notificar os problemas de saúde relacionados ao trabalho, ainda subexistem as indefinições de responsabilidades pela notificação, como pode ser observado a seguir:

[...] realmente meu índice é baixo... quando acontece um acidente, como aconteceu um acidente de trajeto entre Sales Oliveira e Pontal. Ele se acidentou no perímetro de Sales Oliveira e não foi notificado nada em Sales, foi tudo pra Pontal. (Trabalhador da Saúde, Alta Anhanguera)

A Lei estadual nº 9.505 (SÃO PAULO [ESTADO], 1997) estabelece a obrigatoriedade da emissão da Comunicação de Acidente de Trabalho (CAT), a qual é um documento criado pela Previdência Social que obriga a empresa a comunicar ao Instituto Nacional de Seguro Social (INSS) todo acidente ou doença relacionados ao trabalho (BRASIL, 1991). A CAT é um documento oficial que permite o levantamento estatístico dos agravos ocorridos no país, além de assegurar algumas garantias ao trabalhador, como, por exemplo, a estabilidade de um ano no emprego após o afastamento médico em consequência de acidente ou doença relacionados ao trabalho. Porém, é um documento que oferece cobertura apenas aos trabalhadores formais e, ainda assim, exclui os autônomos e as domésticas (LOURENÇO, 2011). Na busca de diminuir a subnotificação, sobretudo das doenças relacionadas ao trabalho, a Previdência Social criou o Nexo Técnico Epidemiológico Previdenciário (NTEP), que explicitou um alto índice de doenças que, antes do NTEP, não estavam sendo notificadas, tais como: sofrimento mental relacionado ao trabalho e as lesões por esforço repetitivo (LER) (MACHADO; SORRATTO, CODO, 2010).

O SUS, como já destacado, vem criando instrumentos epidemiológicos, como o RAAT e o Sinan-NET, para o registro dos agravos independentemente do tipo de contrato de trabalho. Trata-se de seguir o princípio da universalidade. 
Porém, muitas dificuldades ainda se colocam no meio do caminho da notificação de tais agravos. Coaduna com os fatores já indicados, a dificuldade do registro devido à localização da empresa, ou seja, pode ocorrer confusão quanto a quem cabe a responsabilidade do registro, como afirmado durante as oficinas:

[...] só que a empresa não era de Pontal, não era de Sales Oliveira, os trabalhadores também não eram de Sales Oliveira e o problema não foi pra mim... a notificação não foi feita... (Trabalhador da Saúde, Alta Anhanguera)

Mesmo quando existe a clareza quanto à responsabilidade da notificação, o fato da região ser constituída de municípios pequenos, que nem sempre contam com estrutura adequada para o atendimento da demanda, contribui para que os casos mais graves acabem sendo encaminhados para outros municípios.

[...] tem as RAAT de acidentes pequenos, que a gente tem esse atendimento feito no município, agora o problema que a gente acaba enfrentando é que a usina tá entre o município de Patrocínio e Batatais, então, provavelmente, tem atendimentos feitos em Batatais e isso não chega até nós... (Trabalhador, Três Colinas)

Quando o trabalhador vítima de algum agravo à sua saúde é encaminhado para atendimento médico em outro município, pode acontecer de o agravo não ser notificado ou ser notificado e não haver troca de informações entre o município que presta o atendimento e o local de residência ou de trabalho da pessoa atendida. Portanto, quando se trata de situações mais graves, segundo os participantes das oficinas:

[...] às vezes, pelo fato das cidades maiores ter um atendimento mais eficiente, é direcionado pra Orlândia ou São Joaquim da Barra, na minha situação... É, tem mês que a gente nem tem acidente que é a mesma situação da cidade de Nuporanga, certo, que tem uma grande empresa e tem vários acidentes, mas não tem tanta notificação. É isso que ocorre lá. (Trabalhador da Saúde, Alta Anhanguera)

Acompanha as dificuldades de notificação no SUS, o fato de, muitas vezes, a CAT também não chegar até os serviços de saúde do município de origem do trabalhador acidentado, sobretudo quando se trata de trabalhador migrante.

Frise-se que os encaminhamentos a outros municípios são legítimos e seguem a diretriz da regionalização. Contudo, a ausência de normas intermunicipais e de troca de informações gera um mascaramento da realidade. Além disso, ainda persiste o medo que o trabalhador tem de que o preenchimento de algum documento crie dificuldades para o seu empregador, como expressado a seguir:

[...] tem patrão que não quer que funcionário preencha o RAAT, mesmo a gente falando que é mais pra um dado estatístico ele não quer, e acaba não preenchendo, não dá dado nenhum, pra não correr o risco de perder o emprego, né? Mas o que, que a gente vai fazer? (Trabalhador da Saúde, Três Colinas)
Outras dificuldades relacionam-se às estratégias criadas pelas empresas, sobretudo as maiores, para que os agravos não sejam notificados, como indicado:

[...] São Joaquim da Barra é um colegiado... tudo chega lá, vem de Ipuã, Nuporanga, às vezes vem de Sales, depende do agravo que houve, né? Então tudo cai ali no Hospital de São Joaquim da Barra...? (Trabalhador da Saúde, Alta Anhanguera)

O município de São Joaquim é destacado pela lógica da Renast para ser Sentinela, ou seja, pelo seu porte e condições de infraestrutura, deve oferecer atendimentos de ST aos seus munícipes/trabalhadores e das cidades menores, localizadas nas proximidades. Dessa forma, é de se supor que nele haveria uma concentração das notificações dos agravos. Contudo, as ocorrências, sobretudo as mais graves, acabam não sendo atendidas pelo hospital (Sentinela), como explica o entrevistado:

[...] Vamos supor, corte de tendões, isso acontece? Acontece, mas a Usina encaminha pra São Joaquim? Nada, nada. Ela envia tudo pra Ribeirão Preto, numa clínica especializada só pra resolver esse corte de tendão, não aparece mais... não é notificado... (Trabalhador da Saúde, Alta Anhanguera)

Ressalte-se que, entre o que é normatizado tanto em âmbito estadual, quanto federal e a sua aplicação prática no âmbito municipal, existe um hiato de tempo considerável, marcado pelas condições do município quanto à sua arrecadação, ao número de funcionários, à infraestrutura dos serviços, à preparação técnica dos trabalhadores da saúde (e do gestor também), o que deve ser levado em conta na programação das ações do Plano Municipal de Saúde. Além disso, ainda há o jogo de forças e interesses, o que contribui para a não efetivação das ações de ST. Não se trata de colocar toda a responsabilidade pelos registros dos agravos à saúde dos trabalhadores no IST ou no trabalhador da saúde, mas de reconhecer que a construção de um sistema de informação é o primeiro passo para efetivar e consolidar ações mais amplas, no sentido de criar um perfil epidemiológico da morbimortalidade dos trabalhadores que favoreça o conhecimento das situações agressoras à saúde para que assim possam ser transformadas. E isso é uma tarefa da política pública de saúde, para a qual o trabalhador pode contribuir, mas não é o único agente. Tais ações devem ser conectadas ao controle social (LACAZ, 2010).

\section{c) Educação permanente em ST: uma marcante necessidade}

Como já foi dito, o Cerest, a DRS e o GVS da região de Franca têm promovido encontros, seminários, reuniões para discutir a inclusão das ações em ST no cotidiano dos serviços de saúde, bem como a notificação dos agravos. Mais recentemente houve uma aproximação e envolvimento da vigilância 
epidemiológica por meio da implantação e alimentação do Sistema Nacional de Notificação, Sinan-NET (BRASIL, 2004).

Especificamente no caso das ações de vigilância, tem ocorrido um protagonismo do CVS/GVS na realização de cursos de capacitação para inspeções nos ambientes de trabalho, o que envolve análise da qualidade da água consumida pelos cortadores de cana e trabalhadores rurais e visitas às suas moradias.

Assim, pode-se dizer que a pactuação entre os gestores do Colegiado Regional tem estimulado a inserção daquelas ações na rotina dos serviços de saúde, mas elas ainda estão num estágio muito incipiente e heterogêneo. Contribui para a heterogeneidade das ações, a formação profissional dos ISTs e dos fiscais, bastante diferenciada. Em alguns municípios, o fiscal sanitário e o IST têm cursos de nível superior, em outros, cursos técnicos. Visando sanar tal lacuna, durante as oficinas foi enfatizado que o Cerest regional Franca está realizando um curso de especialização em ST, mas que privilegia os candidatos que têm curso de nível superior. Diante disso, vários profissionais (interlocutores e fiscais) reclamaram durante as oficinas, enfatizando que eles são os que estão tentando implantar a política de ST, mas foram preteridos no curso e, assim, quem foi contemplado é outro profissional que tem curso superior, mas que não tem nenhuma familiaridade com a ST e com o que vem sendo feito no município. Dessa maneira, tal importante iniciativa certamente não conseguirá resolver a lacuna na formação em ST por parte dos interlocutores e fiscais.

Frise-se que o despreparo técnico e a falta de tradição dos serviços de saúde nas ações de prevenção e de Visat favorecem uma falsa imagem da realidade, ainda mais quando se trata de problemas que têm pouca visibilidade, como é o caso das doenças relacionadas ao trabalho. Ainda existem muitas dificuldades para o trabalhador conseguir diagnosticar e tratar o seu problema de saúde como oriundo do processo de trabalho, o que acaba também refletindo nos dados relativos aos agravos à saúde dos trabalhadores em âmbito nacional (LOURENÇO, 2009, 2011).

\section{d) Vigilância em ST e o papel dos vários atores}

A partir das oficinas, pode-se afirmar que a ST, nesta região, ainda convive com uma falta de interação maior entre interlocutor em ST e fiscal sanitário.
Nas visitas aos municípios e também durante as oficinas, observou-se que, em alguns deles, existe apenas um profissional responsável pela ST, o que gera uma sobrecarga de trabalho e inviabiliza a construção de ações mais amplas e articuladas.

[...] eu também faço parte da vigilância, [...] tenho que cumprir meu horário [...], então eu fico fechada na farmácia, não dá tempo de eu fazer mais nada [...] eu também sou da vigilância sanitária, eu consigo fazer o básico da vigilância, não consigo atender tudo que tem que atender, meio ambiente, trabalho [...] (Trabalhador da Saúde, Três Colinas)

No entanto, é importante registrar também que se verificou, a partir deste estudo, que começa a ser criada uma estrutura, sobretudo nos municípios maiores, para desenvolver ST, pois, nestes, pode-se dividir a responsabilidade das ações entre o IST e o fiscal sanitário, ou seja, o primeiro participa das reuniões promovidas pelo Cerest, DRS/GVS, e fica responsável em levar as propostas para o seu município e lá implantar as orientações recebidas, ao passo que o segundo é aquele que tem o poder de autoridade sanitária e pode fazer fiscalização nos ambientes de trabalho. Ocorre que os fiscais sanitários, historicamente, estão habituados a tratar mais das questões afeitas aos alimentos, produtos farmacêuticos, controle de vetores do que com as ações em ST, até porque esse campo de conhecimento e intervenção ainda se situa como algo novo no cotidiano desses profissionais.

Muitos municípios não contam com profissionais especializados ou capacitados em ST, em especial no que se refere à Visat, e o aprendizado se dá no dia a dia, mediado pela demanda imediata e, algumas vezes, por cobranças do Cerest ou da DRS/GVS.

A gente foi, ontem, nessa usina fazer a visita, no setor de saúde ocupacional, falamos com a enfermeira responsável. E aí a gente fez essas questões ${ }^{5}$ pra ela... (Trabalhador da Saúde, Anhanguera).

Observe-se que a segunda oficina objetivava a apresentação de alguns dados por parte dos participantes, acerca da situação de trabalho e saúde no seu município. Assim, diante da dificuldade de se obter e registrar as informações por meios próprios, alguns IST recorreram às usinas canavieiras, especificamente ao seu setor de Saúde Ocupacional. Dessa forma, acabaram transmitindo o discurso da usina.

[...] Aí, o que ela falou pra gente, foi o seguinte: que nessa usina, eles visam muito à segurança do trabalhador, entendeu? E realmente, [...] a gente verifica que eles tão muito voltados e preocupados com a saúde dos trabalhadores. (Trabalhador da Saúde, Anhanguera)

\footnotetext{
${ }^{5}$ Esclarece-se que as questões mencionadas pela entrevistada se referem ao roteiro norteador da segunda oficina realizada com os trabalhadores da saúde desta região. Pois, seguindo a metodologia proposta pelo projeto de pesquisa indicado na Introdução deste texto, no segundo encontro os participantes deveriam apresentar as ações de ST que desenvolvem no seu município, com enfoque para o setor agroindustrial canavieiro. Portanto, os participantes receberam um roteiro, com algumas questões, para nortear a sua apresentação, ocorrida no início da segunda oficina.
} 
Destaca-se que apesar de ter a usina sucroalcooleira no seu território de atuação, o IST afirmou que ainda não havia realizado nenhuma ação de inspeção na referida empresa e a visita mencionada ocorreu de modo cordial, com o objetivo de buscar elementos para a participação na oficina. Assim acabou conhecendo apenas aquilo que os técnicos da usina mostraram e do modo como mostraram. Sabe-se que não é interessante para a empresa indicar os reais problemas que agridem a saúde dos seus trabalhadores (LOURENÇO, 2009). É digna de nota a afirmação de que a usina tem uma preocupação muito grande com a saúde dos seus trabalhadores, o que seria expresso pelas campanhas de vacinação realizadas.

[...] a gente, às vezes, participa de algumas campanhas de vacinação [...] Ela orientou a gente, que assim, no setor canavieiro, eles fazem orientações diárias, né? Eles têm os alojamentos que são de muito boa qualidade, né? [...] então, a gente percebeu que eles levam a sério mesmo. (Trabalhador da Saúde, Anhanguera)

É preciso que os técnicos responsáveis pela ST nos municípios tenham uma preparação específica para atuar neste campo, pois, além das necessidades relativas ao conhecimento técnico para reconhecer os perigos e as condições e os processos de trabalho que podem agredir à saúde, ainda existem as dificuldades criadas para ocultar a realidade:

[...] a gente percebe também, aquela história, infelizmente, quando você chega numa empresa do porte de uma usina canavieira, é, queira ou não, eles te bota num canto esperando [...] esse esperar, pra gente, dá a sensação de que eles tá mascarando a coisa, né? Agora, a gente também tem que ter um olhar mais crítico pra não deixar escapar certas coisas, né? (Trabalhador da Saúde, Três Colinas)

Alguns municípios apresentaram ações em ST mais estruturadas:

$\mathrm{E}$ a gente foi fazendo visita, pra ver as condições de moradia [refere-se ao trabalhador rural migrante], fazendo algumas adaptações, melhoramos condições de moradia, mas uma condição mínima de conforto de segurança. (Trabalhador da Saúde, Alta Anhanguera)

[...] quando eu tenho um problema, acidente grave, ou acidente fatal, eu investigo tudo, mando pra ser notificado no Sinan e também os acidentes com menores [...] (Trabalhador da Saúde, Três Colinas)

Os ISTs buscam também pela CAT, mas essa acaba sendo preenchida apenas em situações mais graves: "A CAT é muito difícil, o que a gente recebe mesmo são os RAATs" (Trabalhador da Saúde, Anhanguera).

A falta de preparo e tradição em ST aparece relacionada à dissociação entre assistência e vigilância à saúde:

Nós somos as articuladoras. [Não tem nenhum fiscal da vigilância ajudando vocês?] Não. A gente trabalha com a saúde dos trabalhadores e a gente alimenta os programas, as notificações que chegam [...] A gente não tá muito ligado a esses trabalhadores [...] (Trabalhador da Saúde, Anhanguera)

Convivendo com esses problemas, aparece a falta de estrutura dos municípios, mesmo aqueles que já vêm, em certa medida, realizando ações em ST. Vê-se que ainda há a falta de investimentos na infraestrutura e em recursos humanos: "[...] pra que aconteça vigilância e trabalho no campo, os municípios precisam investir em viaturas e funcionários [...]" (Trabalhador da Saúde, Alta Anhanguera).

Lacaz (2010), citando o estudo de Pignati, realizado no estado do Mato Grosso, enfatiza as diferenças de infraestrutura entre as vigilâncias fitossanitária e sanitária: a primeira é marcada pelo gigantismo dos recursos e, a segunda, pela precarização, o que remete à conclusão que a soja é mais valorizada que o trabalhador.

A região de Franca tem tido a cana-de-açúcar como a principal cultura agrícola e conta com seis usinas sucroalcooleiras. Trata-se de uma nova complexidade, uma vez que a expansão da cultura da cana de açúcar foi acompanhada também da expansão dos problemas sociais, como verificado em estudo anterior (SANT'ANA; CARMO; LOURENÇO, 2011).

Além da dificuldade de se reconhecer em que medida os processos de trabalho agridem a saúde dos trabalhadores, os fiscais sanitários ainda enfrentam problemas quanto aos limites da extensão territorial, na medida em que as atividades da usina estão presentes em vários municípios. Todavia, cada fiscal deve se limitar à sua área distrital. Assim, a usina pode não estar localizada no município onde os trabalhadores estão cortando cana ou desenvolvendo outro tipo de atividade no trato desta cultura, mas se cria uma situação inusitada para estes municípios: alguns vizinhos próximos, outros mais distantes, recebem, em um só dia, uma grande quantidade de trabalhadores:

[...] um exemplo, a usina Vale do Rosário, tem dez frentes de trabalho, ela não é do meu município, mas ela manda pra lá [...] não tem quem fiscalizar [...], se ela ficar hoje e amanhã, segunda feira, ela já foi embora [...] (Trabalhador da Saúde, Alta Anhanguera)

Como indicado, não se trata apenas da questão do acidente em si, porque, no caso dele ocorrer, o trabalhador é atendido no serviço de saúde mais próximo, embora crie uma dificuldade para a notificação. O maior problema é que o município acaba não conseguindo acompanhar este processo de trabalho, como diz o trabalhador da saúde do Alta Anhanguera:

[...] e se aconteceu alguma irregularidade em relação à água ou em relação ao trabalhador, eu não vou ficar sabendo, nem o município de onde ela é [referência à usina], entendeu? [...] 
Quanto aos insumos e à infraestrutura, o SUS local, por meio da Vigilância Sanitária, tem buscado acompanhar a qualidade da água fornecida aos trabalhadores rurais, dos equipamentos de proteção individual (EPI), do local para refeição, dos banheiros, das moradias etc., como se constata no depoimento que se segue:

[...] e a gente tá fiscalizando se essa água tá sendo, de que forma tá sendo levada pra lá, de onde ela tá sendo recolhida, se tá sendo higienizado o tanque de depósito dessa água, enfim, tem um monte de coisa que mesmo que não tendo a indústria instalada no seu município, mas tem essas outras questões de moradia, transporte, água... (Trabalhador da Saúde Anhanguera)

Contudo, apesar de se verificar, por meio dos depoimentos, que alguns municípios desenvolvem ações de vigilância nos ambientes de trabalho, muitos limites são exaltados em decorrência da falta de condição dos técnicos acompanharem o trabalho no campo, sobretudo no corte da cana.

[...] durante as inspeções rotineiras nas usinas, nós verificamos que os trabalhadores recebem o EPI, entendeu? Então, se acontece um acidente no momento de trabalho dele, eu não tenho como ficar sabendo, eu não tenho como fiscalizar todas as frentes o tempo todo, o dia inteiro, porque eu tenho outras coisas pra fazer na vigilância sanitária; mas eu já fiscalizei a usina, eu já sei que ele tem os EPIs, eu já sei que os trabalhadores receberam. (Trabalhador da Saúde Alta Anhanguera)

Ao focar na particularidade da cana, é importante considerar que, na época de safra da colheita, os municípios nem sempre estão preparados para atuarem de modo mais incisivo nestas questões, pois, além da carência de preparação técnica do fiscal sanitário e do IST, chama-se a atenção para o fato de que, em geral, as ações de fiscalização em ST privilegiam mais os aspectos relativos aos ambientes de trabalho e ao uso de EPI, desconsiderando fatores importantes da organização e das relações sociais de trabalho. A par disso existe a falta de tradição do SUS municipal nas ações de Visat. Ademais, no período da safra, há o aumento do trabalho rural, distribuído nas várias frentes de trabalho, como mencionado pelos participantes das oficinas. Portanto, é preciso considerar ainda que esse apresenta algumas peculiaridades em relação ao urbano, facilmente localizado em determinado espaço circunscrito.

No campo, os trabalhadores estão espalhados nas lavouras ou no eito dos canaviais e a identificação dos problemas relacionados ao trabalho necessita de um esforço grande que não se faz sem percorrer alguns quilômetros de terra, muitas vezes pelo canavial adentro (SILVA, 1999).

Assim, em época de colheita, os municípios acabam recebendo um contingente de trabalhadores que ficam espalhados nas várias fazendas ou frentes de trabalho, mas não na condição de moradores. São trabalhadores itinerantes, que residem na cidade em acomodações precárias, como foi apontado e discutido durante as oficinas, e trabalham em lugares distantes e "invisíveis" à vida social daquela cidade, a qual passa a ser para eles apenas o local onde o corpo cansado e exaurido pelo dia de trabalho recarrega, minimamente, as suas energias, ou suas cidades dormitório (SILVA, 1999):

É $[. .$.$] os nossos cortadores de cana, eles trabalham em$ toda a região, temos uma transportadora lá, leva os cortadores de cana pra Pontal, Barretos, Sertãozinho. De Guará a Pontal dá uns 60 km, mas para Sertãozinho dá uns 90 km. (Trabalhador da Saúde, Anhanguera)

Além do desgaste da saúde, do cansaço diário decorrentes do processo de trabalho, ainda há o percurso de casa-trabalho-casa. Soma-se a isso a precariedade das moradias dos trabalhadores rurais, sobretudo dos cortadores de cana, que estimulou ações de inspeção por parte da Vigilância Sanitária regional em resposta aos pedidos do Ministério Público do Trabalho:

[...] a gente tem já desenvolvido junto com o Procurador Federal do Trabalho de Campinas, fiscalização em moradias que o próprio Procurador mandou pra nós o endereço, com isso a gente viu uma melhora. (Trabalhador da Saúde, Alta Anhanguera)

Todavia, a fiscalização nas moradias não é uma prática desenvolvida por todos os municípios. $\mathrm{Na}$ realidade, verificou-se durante as oficinas que este tipo de atuação, decorrente de solicitações por parte do Ministério Público do Trabalho, ocorre apenas em alguns municípios. Além de não se configurar como uma prática uniforme entre todas as vigilâncias, ainda existe o fato de o trabalhador rural residir em um determinado município e trabalhar em outro:

[...] o problema maior, eu acredito, não é tanto São Joaquim, e sim as cidades circunvizinhas [...] em Joaquim já fica difícil, hoje em dia, pra arrumar casa [...] como eles não arrumam casa, então vai pras cidades circunvizinhas de São Joaquim. (Trabalhador da Saúde, Alta Anhanguera)

Há também que se considerar que, além da especificidade do trabalho na agricultura, marcado pelo período de safra e entressafra, ainda há o processo de proletarização e de desemprego no campo proporcionado pela "modernização" da agricultura, a qual criou uma massa assalariada itinerante que fica submetida a uma maior mobilidade, ou seja, um dia trabalha em um lugar, noutro em outro e, assim, por diante. Essa é uma dificuldade premente: não ter um lugar fixo de trabalho. O trabalho volante, de boia-fria ou temporário, é o resultado do modelo de agricultura baseado na concentração de terras e na monocultura. Ianni (1977, p. 47) já havia indicado que: 
Ele tem sido chamado boia-fria, pau-de-arara, volante, trabalhador temporário, diarista ou outras denominações. Ao lado do usineiro e do IAA [Instituto de Açúcar e Álcool], ele simboliza o caráter das relações de produção imperante na agroindústria açucareira de Sertãozinho.

O autor reconhece também a presença de muitos outros personagens, tais como:

[...] administrador, capataz, feitor, fiscal, engenheiro, químico, tratorista, motorista, empreiteiro de mão de obra, trabalhador permanente, trabalhador temporário, mecânico, foguista, eletricista, colono, mensalista, diarista, servente etc. (IANNI, 1977, p. 48)

No entanto, o autor enfatiza que o boia-fria é o trabalhador mais característico das relações de produção imperantes na agroindústria açucareira. Atualmente, esse trabalhador sofre os impactos do desemprego proporcionado pela mecanização do corte da cana-de-açúcar (SANT'ANA; CARMO; LOURENÇO, 2011).

O trabalho itinerante pode representar inúmeros problemas para a organização política dos trabalhadores, uma vez que, a cada semana, o trabalho é desenvolvido em um lugar com características diferentes (SILVA, 1999). Além disso, a distância entre o lugar onde mora e o local de trabalho também deve ser considerado, como referido:

Nós temos cortadores que vão pra Uberlândia, a usina [...] que é $200 \mathrm{~km},[\ldots]$ mas é o pessoal que vem de fora e eles devem ser contratados de qualquer jeito, assim [...] mora em Igarapava e vão [...] duas horas e meia de viagem, de transporte, tanto é que levantam 3 horas da manhã. (Trabalhador da Saúde, Anhanguera)

Esta instabilidade do trabalho, uma vez que não se tem um contingente fixo de trabalhadores rurais ou cortadores de cana por município, como foi referido, faz com que, em poucos dias, os trabalhadores já não estejam mais na mesma localidade. Isso favorece a falta de comprometimento dos governos municipais em efetivar ações mais amplas e incisivas neste setor, em um contexto de distanciamento do movimento de trabalhadores pela defesa da saúde e melhores condições de vida e trabalho (LACAZ, 2010).

A "itinerância" do trabalho cria certos distanciamentos, por exemplo, com a base sindical a que o trabalhador pertence (THOMAZ JUNIOR, 2002). São problemas que se repetem, cotidianamente, e provocam rupturas de vínculos, de pensamentos e de classe, reduzindo a luta política por melhores condições de trabalho à mera remuneração pelas horas gastas até se chegar ao trabalho ou retornar deste, como é o caso da hora in itinere, que, apesar de importante, não resolve o problema e pode provocar sentimentos de resignação.

Entre as inúmeras dificuldades que o fiscal sanitário enfrenta para realizar vigilância em ST, desta- ca-se, ainda, a responsabilidade das ações que, no cotidiano, pode ficar confusa quanto a quem deve fiscalizar quando a empresa empregadora é de outro município:

Pelo fato de voltar naquela questão, quem fiscaliza quem, quando um tá no município do outro, não é somente na questão de notificação, é questão de fiscalização. [...] porque se a frente da Vale do Rosário que é de Morro Agudo tá em Sales [...], ela também não tem condição de sair lá de Morro Agudo pra fiscalizar a frente que tá lá em Sales Oliveira, entendeu? Falta viatura e falta gente [...] (Trabalhador da Saúde, Alta Anhanguera)

Ademais, frise-se a necessidade de preparação técnica, pois cada vigilância municipal deve agir no seu território, mas como o trabalho rural, em especial a colheita da cana, tem a especificidade da mobilidade dos trabalhadores e ocorre a sua onipresença nestes municípios, é preciso que os municípios próximos se organizem e realizem ações integradas, como foi reforçado durante as oficinas.

\section{Considerações finais}

A coleta de dados por meio de oficinas favoreceu a participação dos sujeitos para além da simples elucidação dos problemas, criando um ambiente propício ao envolvimento dos participantes no debate e na busca de alternativas que ofereçam apontamentos para o possível enfrentamento dos problemas.

Em alguns municípios, ou faltam profissionais, ou não há vontade política para designar profissionais para as ações de ST. Assim, pode ocorrer de o município contar com apenas um técnico (interlocutor ou fiscal sanitário) para implantar, acompanhar e fazer Visat. Nesse ínterim, é forçoso destacar que nenhum desses profissionais - IST ou fiscal sanitário - está afeito apenas às ações de ST. Na realidade, há um acúmulo de funções e a ST chega para eles como mais uma função ou mais uma tarefa.

Nos últimos anos, a ST no SUS contou com uma série de normas e portarias que garantem a sua configuração no contexto da política pública de saúde. Contudo, no dia a dia dos serviços de saúde, ainda sobressaem problemas simples, mas muito sérios, como a descontinuidade das ações, ora porque não se tem funcionários preparados tecnicamente, ora porque houve a sua substituição, outras vezes porque não se documentam as ações e, como não há uma definição clara nas agendas municipais da ST, também não há quem as cobre (LACAZ, 2010).

Enfim, salta aos olhos a não uniformidade da implantação das ações de ST. Em alguns municípios, são incipientes, em outros, já estão mais organizadas, como demonstram os depoimentos que destacam as 
visitas às moradias dos trabalhadores rurais e a investigação de acidentes de trabalho graves, sobretudo os acidentes que envolvem crianças, adolescentes, amputações e mortes, como preconizado inicialmente pela Portaria n⿳ำ 777, do Ministério da Saúde (BRASIL, 2004), e atualmente pela Portaria $n^{\circ} 104$, que define as terminologias e a notificação compulsória das doenças relacionadas ao trabalho (BRASIL, 2011a). Acompanha essa realidade a falta de preparação técnica para as ações em saúde do trabalhador e, ainda, o acúmulo de tarefas a que os ISTs e os fiscais sani- tários estão submetidos. Assim, se falta preparação técnica para fazer ST e se, ao mesmo tempo, o interlocutor e/ou fiscal, no caso da região de Franca, são responsáveis por várias outras ações, é de se esperar que a prioridade de trabalho seja para aquilo que é mais familiar e faz parte da rotina. Como se viu no caso aqui relatado, mesmo em uma região importante tanto do ponto de vista industrial, como agrícola, em muitos municípios a ST ainda não faz parte da rotina dos seus serviços de saúde e das prioridades da gestão municipal de saúde!

\section{Contribuições de autoria}

Os autores contribuíram igualmente para a realização deste trabalho.

\section{Referências}

BRASIL. Decreto $\mathrm{n}^{\circ}$ 7.602, de 07 de novembro de 2011b. Dispõe sobre a Política Nacional de Segurança e Saúde no Trabalho - PNSST. Disponível em: < http:// www.planalto.gov.br/CCIVIL_03/_Ato2011-2014/2011/ Decreto/D7602.htm>. Acesso em: 22 jan. 2012.

Lei $n^{\circ}$ 8.213, de 24 de julho de 1991. Dispõe

sobre os Planos de Benefícios da Previdência

Social e dá outras providências. (Atualizada até

Setembro - 2011). Diário Oficial [da] República

Federativa do Brasil, Brasília, DF, 14 ago. 1991.

Disponível em: < http://www81.dataprev.gov.br/sislex/ paginas/42/1991/8213.htm > . Acesso em: 9 jun. 2010.

. Ministério da Saúde. Colegiado de Gestão

Regional na Região de Saúde Intraestadual:

orientações para organização e funcionamento, Série

B. Textos Básicos de Saúde. Brasília, DF: Ministério da Saúde, 2009a. (Série Pactos pela Saúde 2006, v. 10). Disponível em: <http://bvsms.saude.gov.br/bvs/ publicacoes/pacto_saude_volume10.pdf $>$. Acesso em: 22 mar. 2013.

Ministério da Saúde. Portaria Federal $\mathrm{n}^{\underline{0}}$ $\overline{777 / G M}$, de 28 de abril de 2004. Dispõe sobre os procedimentos técnicos para a notificação compulsória de agravos à saúde do trabalhador em rede de serviços sentinela específica, no Sistema Único de Saúde SUS. Disponível em: < http://dtr2001.saude.gov.br/sas/ PORTARIAS/Port2004/GM/GM-777.htm>. Acesso em: 13 jan. 2012.

. Ministério da Saúde. Portaria nº 104, de 25 de janeiro de 2011a. Define as terminologias adotadas em legislação nacional, conforme o disposto no Regulamento Sanitário Internacional 2005 (RSI 2005), a relação de doenças, agravos e eventos em saúde pública de notificação compulsória em todo o território nacional e estabelece fluxo, critérios, responsabilidades e atribuições aos profissionais e serviços de saúde. Disponível em: < http:// bvsms.saude.gov.br/bvs/saudelegis/gm/2011/ prt0104_25_01_2011.html>. Acesso em: 9 jun. 2012.

. Ministério da Saúde. Portaria nº 2.437/GM, de 07 de dezembro de 2005. Dispõe sobre a ampliação e o fortalecimento da Rede Nacional de Atenção Integral à Saúde do Trabalhador - Renast no Sistema Único de Saúde - SUS e dá outras providências. Disponível em: <http://dtr2001.saude.gov.br/sas/PORTARIAS/Port2005/ GM/GM-2437.htm>. Acesso em: 13 jan. 2012.

. Ministério da Saúde. Portaria nº 2.728, de 11 de novembro de 2009b. Dispõe sobre a Rede Nacional de Atenção Integral à Saúde do Trabalhador (Renast) e dá outras providências. Disponível em: < http://portal. saude.gov.br/portal/arquivos/pdf/portaria_renast_2728. pdf $>$. Acesso em: 15 fev. 2012.

Ministério da Saúde. Secretaria de Atenção à Saúde. Departamento de Ações Programáticas Estratégicas. Portaria $\mathrm{n}^{\mathrm{o}}$ 1.679, de 19 de setembro de 2002. In: BRASIL. Legislação em saúde do trabalhador: caderno de legislação em saúde do trabalhador. 2. ed. rev. ampl. Brasília: Ministério da Saúde, 2005. p. 114-129.

DIAS, E. C.; HOEFEL, M. G. O desafio de implantar as ações de saúde do trabalhador no SUS: a estratégia da Renast. Ciência \& Saúde Coletiva, Rio de Janeiro, v. 10, n. 4, p. 817-828, 2005.

IANNI, O. A classe operária vai ao campo. 2. ed. São Paulo: Brasiliense, 1977. (Caderno CEBRAP, n. 24).

INSTITUTO BRASILEIRO DE GEOGRAFIA E

ESTATÍSTICA. Cidades. Disponível em: < http://www. ibge.gov.br/cidadesat/topwindow.htm?1>. Acesso em: 22 maio 2012.

LACAZ, F. A. C. O campo Saúde do Trabalhador: resgatando conhecimentos e práticas sobre as relações trabalho-saúde. Cadernos de Saúde Pública, Rio de Janeiro, v. 23, n. 2, p. 757-766, 2007. 
. Política Nacional de Saúde do Trabalhador: desafios e dificuldades. In: LOURENÇO, E. A. S. et al. (Org.). O avesso do trabalho II: trabalho, precarização e saúde do trabalhador. São Paulo: Expressão Popular, 2010. p. 199-230.

Saúde do trabalhador: um estudo sobre as formações discursivas da academia, dos serviços e do movimento sindical. 1996. 435 f. Tese (Doutorado em Medicina)-Faculdade de Ciências Médicas, Universidade Estadual de Campinas, Campinas, 1996. Disponível em: <http://www.bibliotecadigital. unicamp.br/document/?code $=000114922 \& f d=y>$. Acesso em: 21 jun. 2013.

LOURENÇO, E. A. S. Agravos à saúde dos trabalhadores no Brasil: alguns nós críticos. Revista Pegada, Presidente Prudente, v. 12, n. 1, 2011. Disponível em: <http://revista.fct.unesp.br/index.php/pegada/article/ view/927/940 > . Acesso em: 14 fev. 2011.

. Na trilha da saúde do trabalhador: a experiência de Franca. 426 f. Tese (Doutorado em Serviço Social)Programa de Pós-Graduação em Serviço Social, Universidade Estadual Paulista. Franca: Unesp, 2009. Disponível em: <http://www.franca.unesp.br/Home/ Pos-graduacao/ServicoSocial/edvania.pdf $>$. Acesso em: 21 jun. 2013.

MACHADO, J.; SORRATTO, L.; CODO, W. Saúde e trabalho no Brasil: uma revolução silenciosa. O NTEP e a Previdência Social. Petrópolis: Vozes, 2010.

MAENO, M.; CARMO, J. C. Saúde do trabalhador no SUS. São Paulo: Hucitec, 2005.

MARX, K. O capital: crítica da economia política. 19. ed. Rio de Janeiro: Civilização Brasileira, 2002. Livro 1, v. 1-2.

MINAYO-GOMEZ, C. Campo saúde do trabalhador; trajetória, configuração e transformações. In: MINAYOGOMEZ, C.; MACHADO, J. M. H.; PENA, P. G. L. Saúde do trabalhador na sociedade brasileira contemporânea. Rio de Janeiro: Fiocruz, 2011, p. 23-34.

RIBEIRO, H. P. O juiz sem a toga: um estudo da percepção dos juízes sobre trabalho, saúde e democracia no judiciário. Florianópolis: Lagoa, 2005.

SANT'ANA, R. S.; CARMO, O. A.; LOURENÇO, E. A. S. Questão agrária e saúde do trabalhador: desafios para o século XXI. São Paulo: Unesp-Cultura Acadêmica, 2011.

SANTOS, A. P. L.; LACAZ, F. A. C. Saúde do trabalhador no SUS: contexto, estratégias e desafios. In: MINAYO-GOMEZ, C.; MACHADO, J. M. H.; PENA, P. G. L. (Org.). Saúde do trabalhador na sociedade brasileira contemporânea. Rio de Janeiro: Fiocruz, 2011, p. 87-105.

SÃO PAULO (Estado). Lei Estadual no 9.505, de 11 de março de 1997. Disciplina as ações e os serviços de saúde dos trabalhadores no Sistema Único de Saúde. Disponível em: < http://ww2. prefeitura.sp.gov.br//arquivos/secretarias/saude/ legislacao/0007/LeiEstadual_1997_9505.pdf>. Acesso em: 9 jun. 2010.

SILVA. M. A. M. Errantes do fim do século. São Paulo: Editora da Unesp, 1999.

THOMAZ JUNIOR, A. Por trás dos canaviais, os "nós" da cana: a relação capital x trabalho e o movimento sindical dos trabalhadores na agroindústria canavieira paulista. São Paulo: Annablume/Fapesp, 2002.

VASCONCELOS, L. C. F.; MACHADO, J. M. H. Política Nacional de Saúde do Trabalhador: ampliação do objeto em direção a uma política de Estado. In: MINAYO-GOMEZ, C.; MACHADO, J. M. H.; PENA, P. G. L. (Org.). Saúde do trabalhador na sociedade brasileira contemporânea. Rio de Janeiro: Fiocruz, 2011, p. 37-65. 